\title{
New Approach for Global Education - Simulating Supply Chains by Applying World Wide Web
}

\author{
Karl-Robert Graf ${ }^{1}$, Siegfried Augustin ${ }^{2}$ and Konstantinos Terzidis ${ }^{3}$
}

1) Fachhochschule Karlsruhe, Fachbereich Wirtschaftsinformatik, Moltkestrasse 30, D-76133 Karlsruhe, Germany.

Email: Robert.Graf@fh-karlsruhe.de

2) Schulstrasse 36/2, D-80634 München, Germany. ProfAugustin@aol.com

3) Technological Educational Institute of Kavala, Department of Information Management, P.O. Box 1194, GR 65404 Kavala, Greece.

Email:kter@teikav.edu.gr

Abstract: $\quad$ For a long time simulation tools have been used for implementing logistic functions and connections in teaching and vocational training (AUGUSTIN, GRAF 1995; Riis 1995; WIENDAHL 1996; LANG, JUNG 2001). In recent years, considerable progress has been made with regard to the following different ways and means used in logistics and computer science: Transformation of the logistics management into a fundamentally enlarged supply chain management, establishment of communication, set-up of business tools like B2B (Business to Business), B2C (Business to Customer), the Internet, ecommerce (Electronic Commerce), etc. for the efficient functioning of a supply chain, and development of new programming software for the open and distributed implementation of training modules in local and global networks. As part of a project, traditional aspects are going to be enhanced by current methods and concepts so that new interdisciplinary work methods can be applied in business networks. For this purpose the training medium "business simulation" is going to be brought to the state-of-the-art in computer, communication and network technology. Within the scope of a joint project of private industry partners (Siemens AG) and different universities (Montanuniversität Leoben, Austria; Technological Educational Institute of Kavala, Greece) a training concept is being developed, completing traditional logistics aspects (planning and control of intra-company material, purchase orders and information flow) by the previously mentioned new requirements.

Keywords: Logistics, Supply chain management, Simulation, Blended learning, E-Learning, Personal development, Web based training 


\section{INTRODUCTION}

For a long time simulation tools have been used for implementing logistic functions and connections in teaching and vocational training (AUGUSTIN, GRAF 1995; RIIS 1995; WIENDAHL 1996; LANG, JUNG 2001). In recent years, considerable progress has been made with regard to the following different ways and means used in logistics and computer science (see Figure 1):

- Transformation of the logistics management into a fundamentally enlarged supply chain management,

- Establishment of communication, set-up of business tools like B2B (Business to Business), B2C (Business to Customer), the Internet, ecommerce (Electronic Commerce), etc. for the efficient functioning of a supply chain,

- Development of new programming software for the open and distributed implementation of training modules in local and global networks.

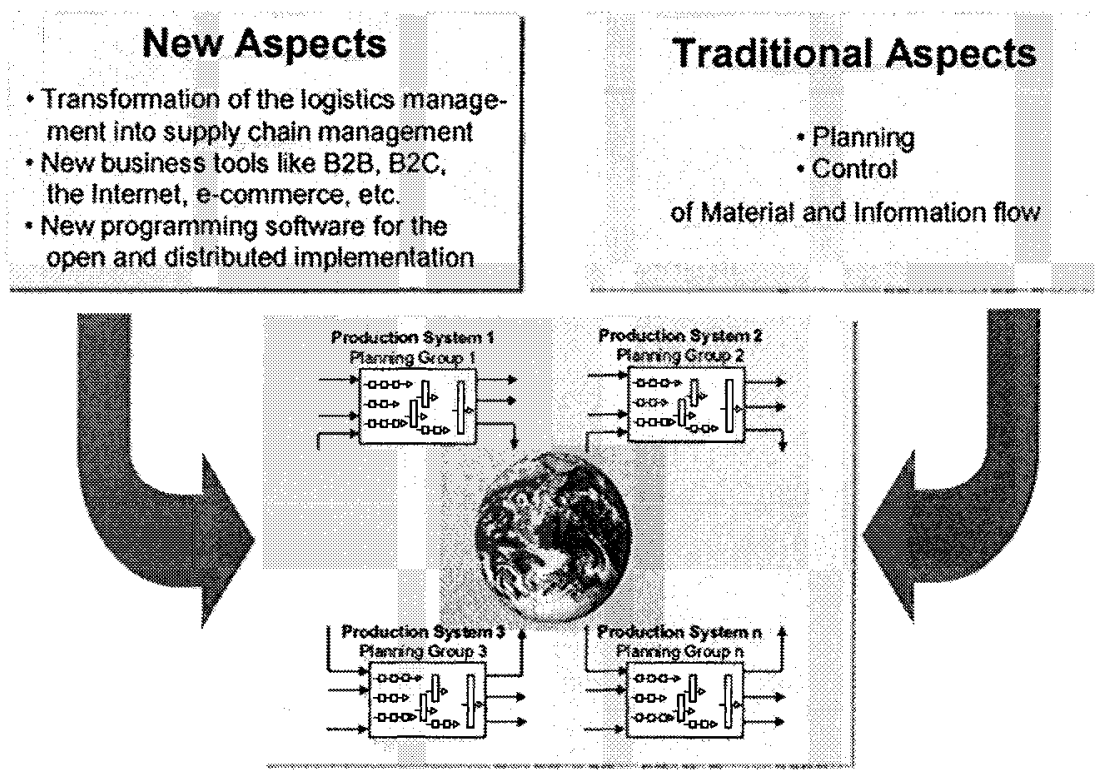

Figure 1. New aspects vs. traditional aspects

As part of a project, traditional aspects are going to be enhanced by current methods and concepts so that new interdisciplinary work methods can be applied in business networks. For this purpose the training medium "business simulation" is going to be brought to the state-of-the-art in computer, communication and network technology. 
Within the scope of a joint project of private industry partners (Siemens AG) and different universities (Montanuniversität Leoben, Austria; Technological Educational Institute of Kavala, Greece) a training concept is being developed, completing traditional logistics aspects (planning and control of intra-company material, purchase orders and information flow) by the previously mentioned new requirements.

The goal of this project is the establishment of a simulated model system in which several value-added partners (located in various geographical areas) of a supply chain are involved (THALER 1999). The exchange of merchandise between those partners is going to be implemented via B2B, B2C, ecommerce, or similar solutions on a virtual market-place. The virtual market place and its conditions need to be set up in a simulation model that allows the value-added partners to plan and reorganize their businesses leading and interactions to the creation of an operating supply chain.

\section{DESCRIPTION OF THE SIMULATION MODEL}

The value-added partners shown in the simulated model system are planned by one training group each, so they can act and cooperate on a common virtual market, independent of their geographical location. This enables various training groups from different fields and universities to participate in the business simulation at the same time.

All groups are starting with an identical model company in which three products are manufactured. The in-house manufactured products consist of parts and components, and the purchased parts. The participating groups plan the production system simulated in the model (see Figure 2). The planning comprises:

- the release of purchase orders,

- production orders,

- production capacities for the working units and

- control methods.

At the starting point the participating groups work in an isolated model world. Parts to be purchased are obtained from an anonymous source of supply under various conditions. At the other side there is an anonymous salesmarket with its primary and supplementary requirements. So the production units and planning groups design their system for markets that are almost nearly independent of each other (see Figure 3). 
Purchasing

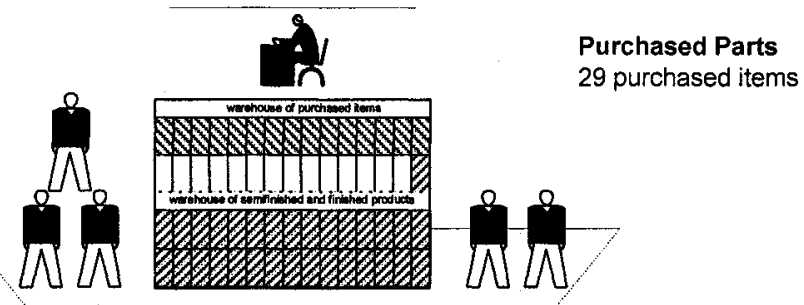

Parts Production

5 work places

Pre-fabrication
8 work places

Final Assembly

1 work place

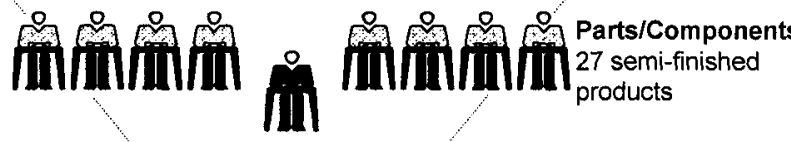

Sales Department

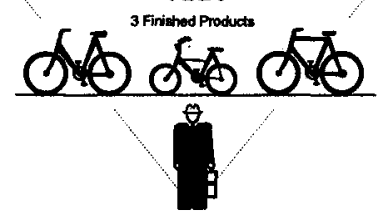

Products

3 finished products

Figure 2. Elements of the production system

In the following, the groups have the chance to carry out successively their exchange of goods on a newly installed central market. The production units and planning groups design their systems on a common open market (see Figure 5).

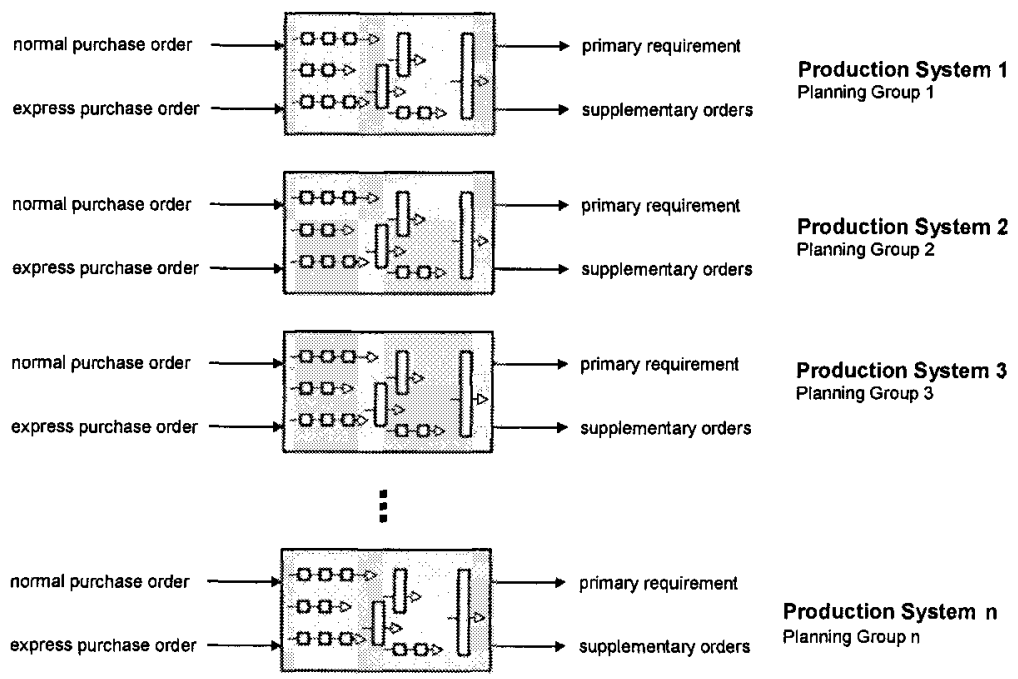

Figure 3. Isolated model structure: Traditional View of Logistics and Production Systems and the TCP Training Concept 
In accordance with principles of Supply Chain Management, the procurement and distribution market is transparent and allows for flexibility new customer and supplier relations. Each group can act on the common market as a customer, or supplier for parts, semi-finished products, and final products (see Figure 4).

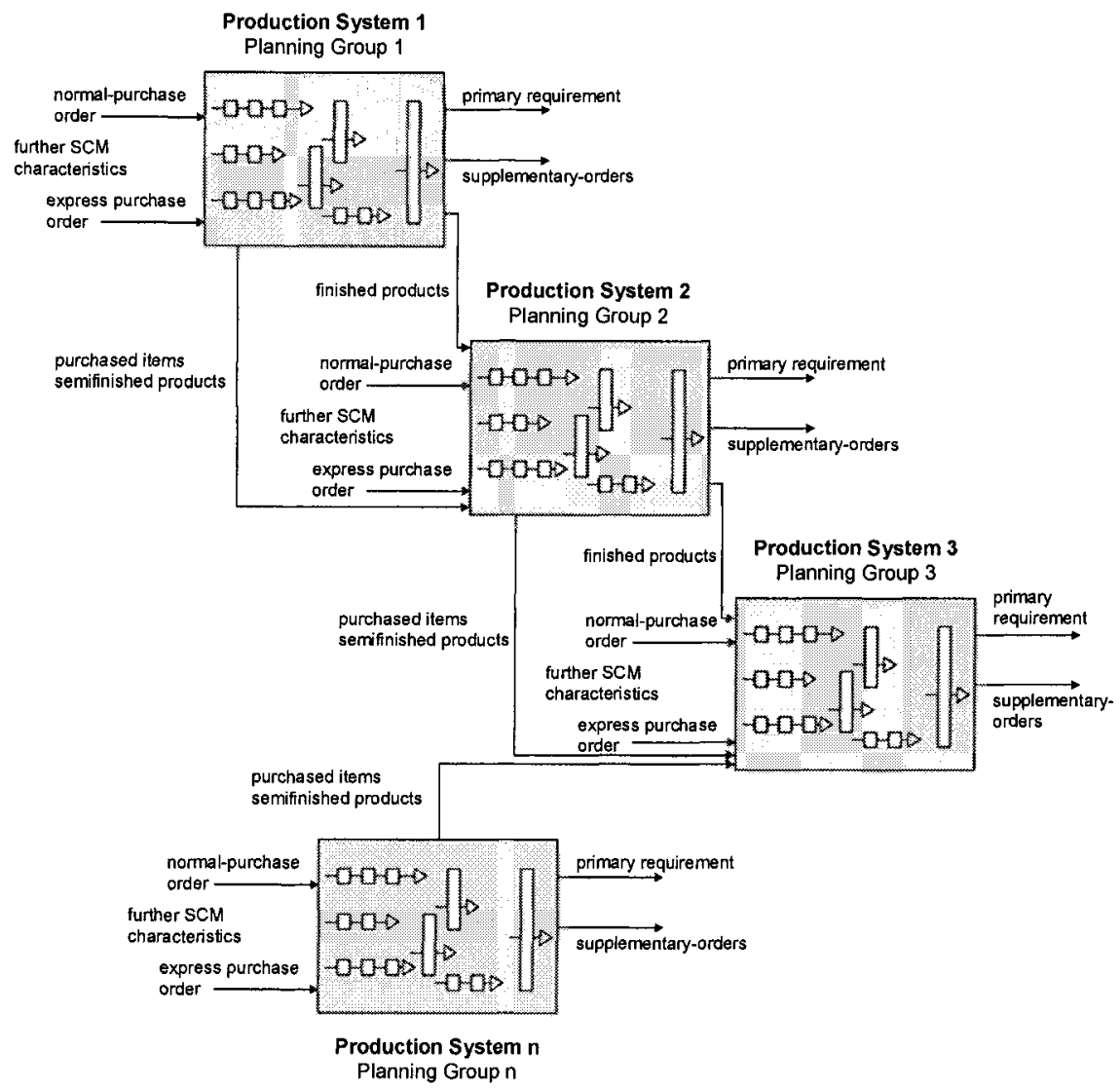

Figure 4. Advanced model structure: New View of Market Supply Chains and the SCS Training Concept

(Source: GRAF, TERZIDIS, AUGUSTIN 2003, p. 28)

Various characteristics within the newly established, Internet-based business relations are possible for the creation of customer-supplier relations (business relations). A concept for three characteristic stages has been set up (see Figure 5).

- Stage 1: Business Relations 1 (Market Place) for Parts, Semi-finished and Finished Products: Open to all suppliers and customers. Suppliers 
and customers alike determine the conditions according to their company situation and market observations.

- Stage 2: Business Relations 2 (B2C, B2B, A2A (Application to Application) for Parts, Semi-finished and Finished Products: The production units coordinate exclusive supply strategies. The conditions result from their company situation and the holistic formation of the supply chain to the advantage of all participants.

- Stage 3: Business Relations 3 (Traditional Market) for Parts, Semi-finished and Finished Products: Anonymous (traditional) market for suppliers and customers with somewhat limited influence by the groups.

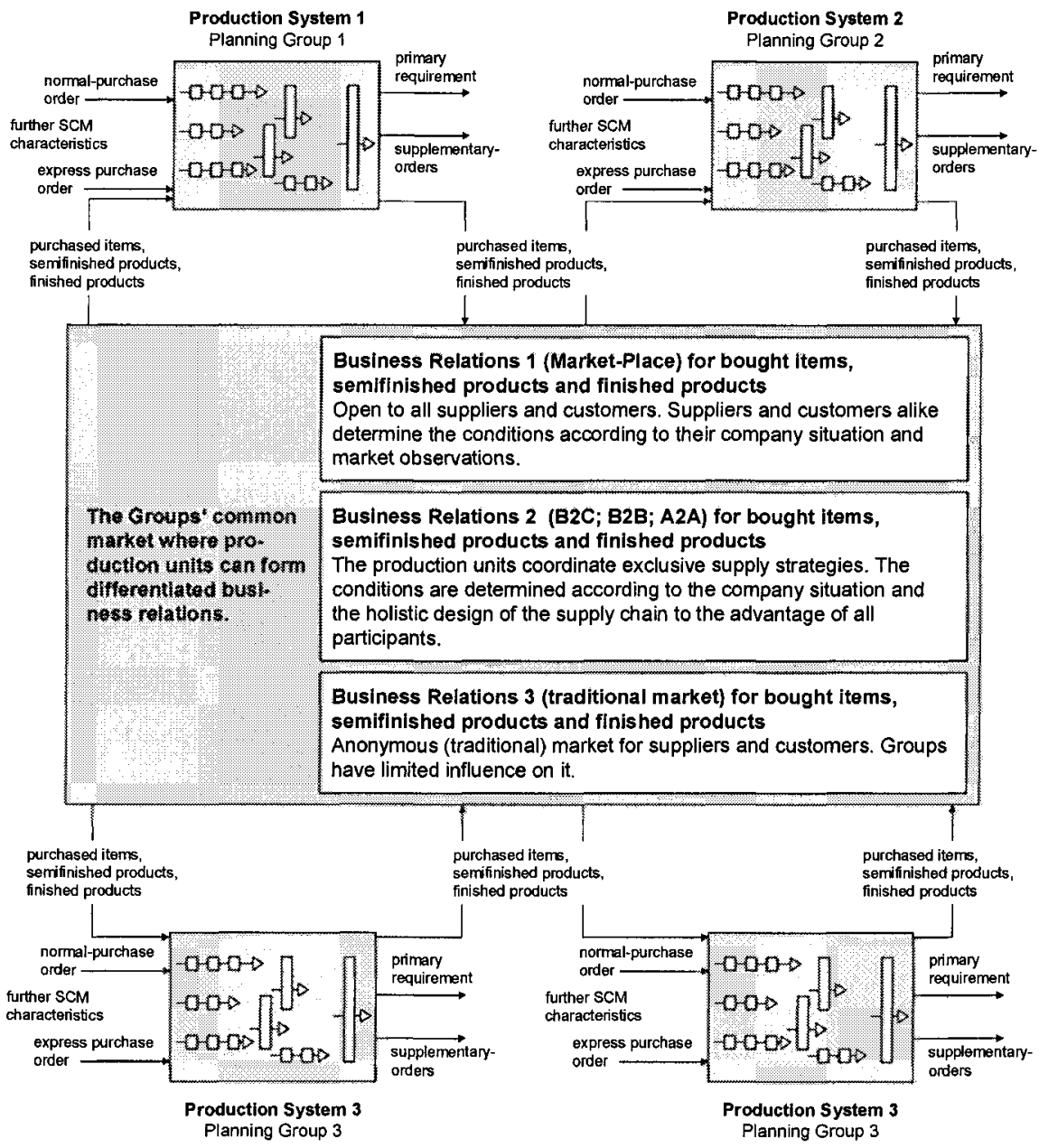

Figure 5. E-Business scenarios

(Source: GRAF, TERZIDIS, AUGUSTIN 2003, p. 30) 
Business relations 1 and 3 have been technically implemented in the current system. Business Relations 2 are going to be realized in this time.

The traditional implementation of the business simulation was as follows: Regionally separate business simulations at various universities and locations showed a model design that was completely independent of the others. In the same way the different groups within a business simulation acted as suppliers and customers on an anonymous market and had very little exchange and contact with each other (see Figure 6).

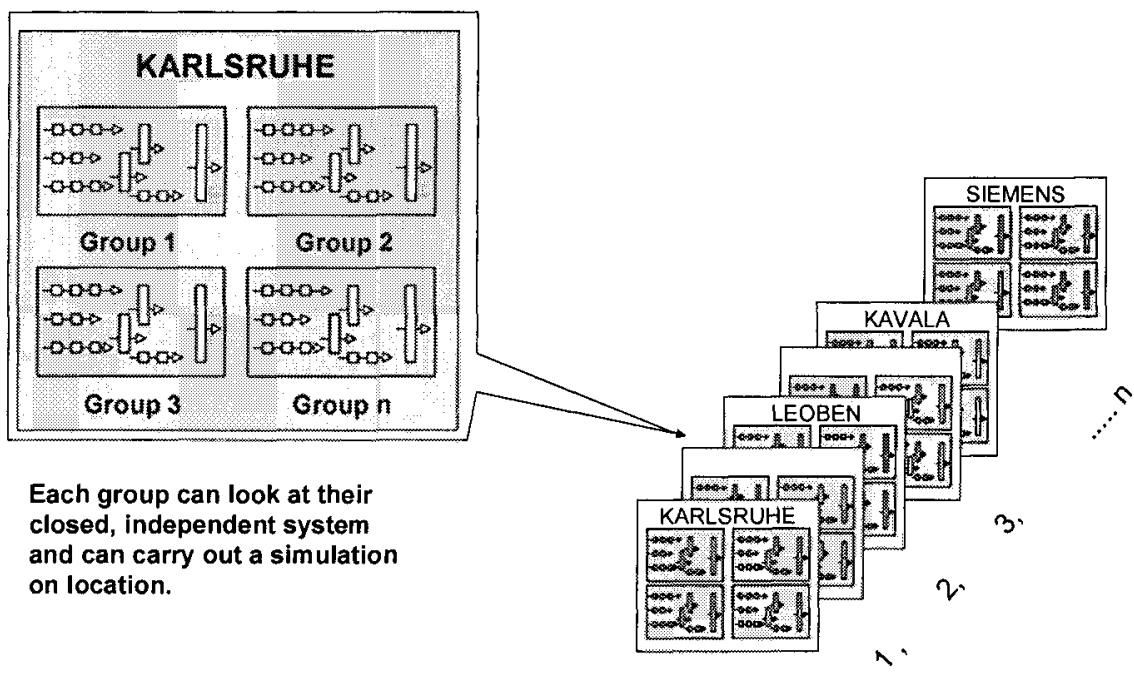

Figure 6. Proven structure

In contrast to the traditional model, Web integration between different business simulations and their participating groups open up completely new methods and possibilities. It allows the groups to act independently of their location - since the simulation of the model companies, as well as the exchange of products, take place via the Internet on a central server in a virtual environment (see Figure 7).

Each group, regardless of their integration into a particular business simulation, has the chance to participate on the common market. The time frame and location of a simulation game thus become irrelevant, as each time the groups that are currently present interact with each other group present on the market. 


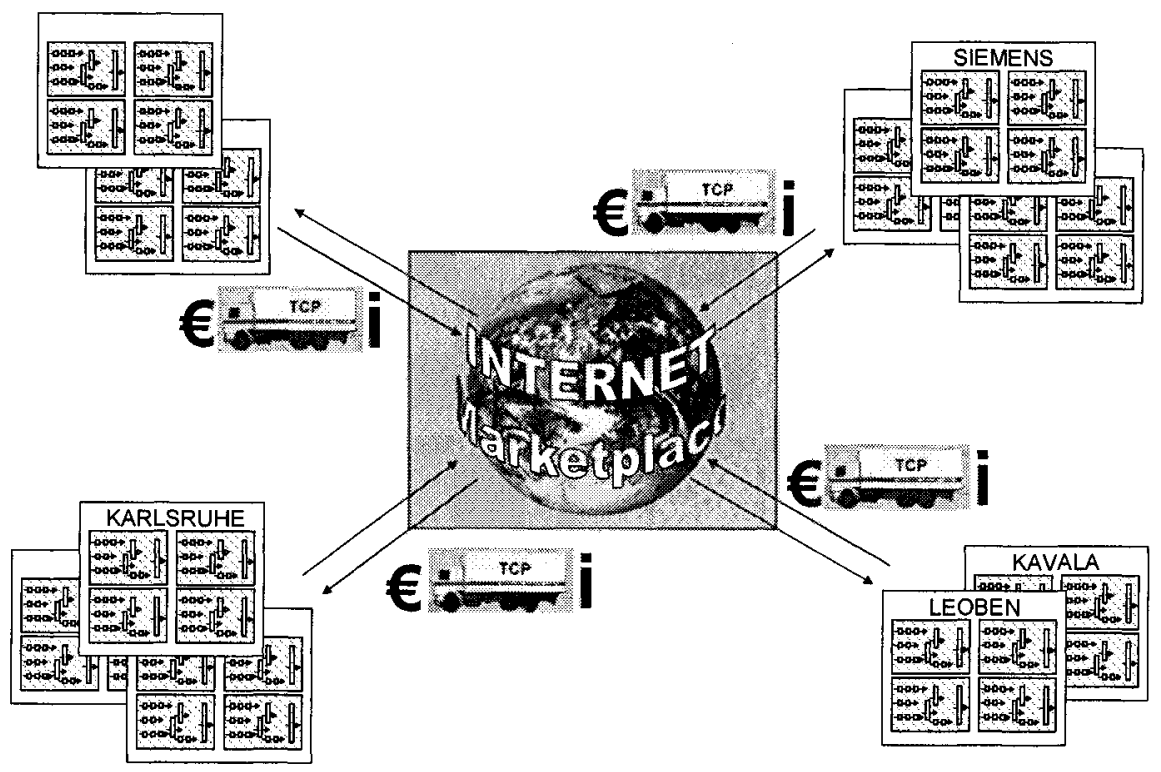

Figure 7. Web integration

(Source: GRAF, TERZIDIS, AUGUSTIN 2003, p. 31)

\section{IMPLEMENTATION AND PROJECT STATUS}

The core of this logistics training concept is a computer simulation of various industrial companies (value partners) for which a new simulation model, adjusted to the previously mentioned conditions, has been developed based on a well-established simulation concept (TCP - Training Centre Production (JUNG 2000; DGP 2004). The simulation of the production system and marketplace resides on a central application-server that participants can access via the Internet, or an Intranet and an interposed web server. According to the requirements in information technology, the implementation is carried out via the programming languages and scripting languages Java, HTML, XML, and SVG (see Figure 8).

The simulation is run via web portal. The currently available portal functions are (see Figure 9):

- data transfer via XML file,

- data input via Applet,

- simulation,

- user administration,

- market-place activities, 
- result evaluation,

- simulation manual and simulation documentation,

- links.

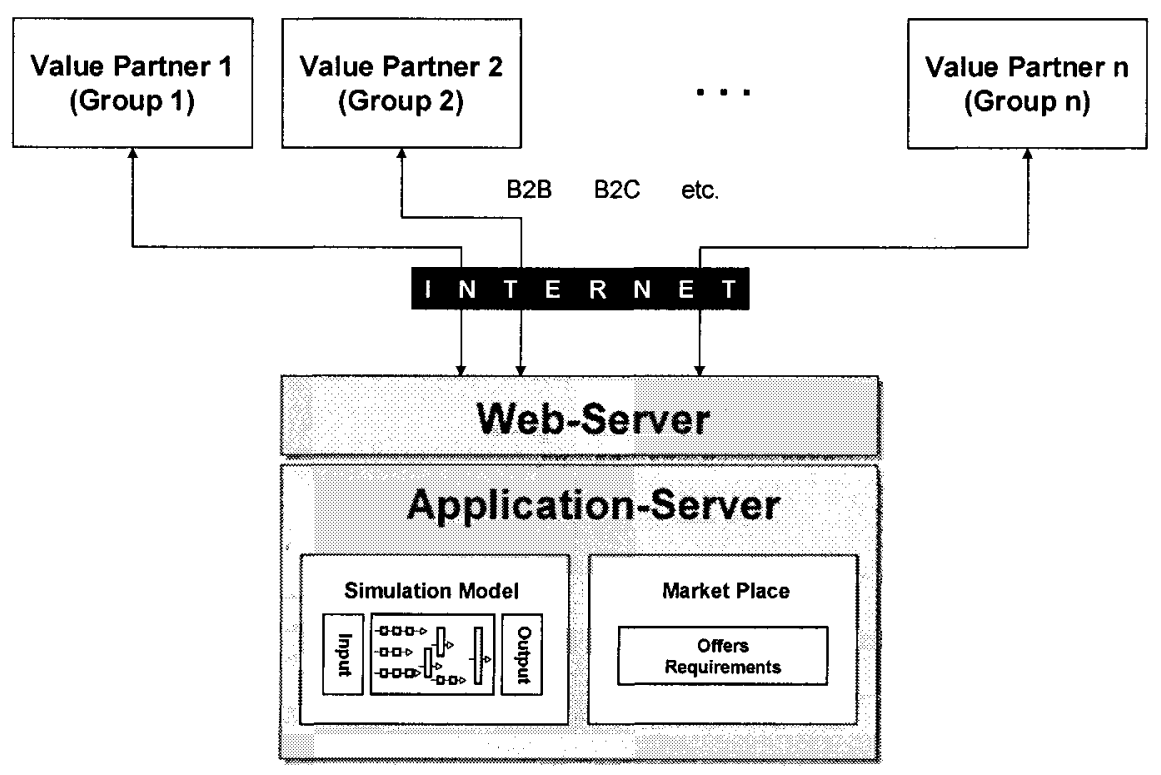

Figure 8. Simulated model system

Different language versions currently exist in English, German and Greek. All the information material necessary for the business simulation has been integrated into the web portal. The participants can access this material any time. The material includes: an electronic manual, all the forms necessary for the business simulation and field specific presentations.

\section{CONCLUSION}

In summary one can say that the idea to implement a global teaching and training concept with this new simulation system has been realized. The concept allows simulation and training in the field of extensive logistics methods and measures using new information technologies combined with new logistics concepts for supply chain management. Modern media and especially the internet, open and blend new opportunities for e-learning. E.g. as special training aspects by means of web integration can be mentioned:

- Creation of a dynamic cooperation among groups

- Groups are formed beyond the borders of universities and departments 
- Training and work of the groups is independent of regional restrictions (internet connection necessary)

- Multilingual implementation is enabled via translated versions of the simulation tools

- Product and cash flow are simulated via the internet

- Information flow takes place according to the current methods on the free market and is trained in the business simulation

- Access to manuals, training materials, and assistance via the internet

- Web integration provides additional information for the participants

- Number of participants can be increased any time

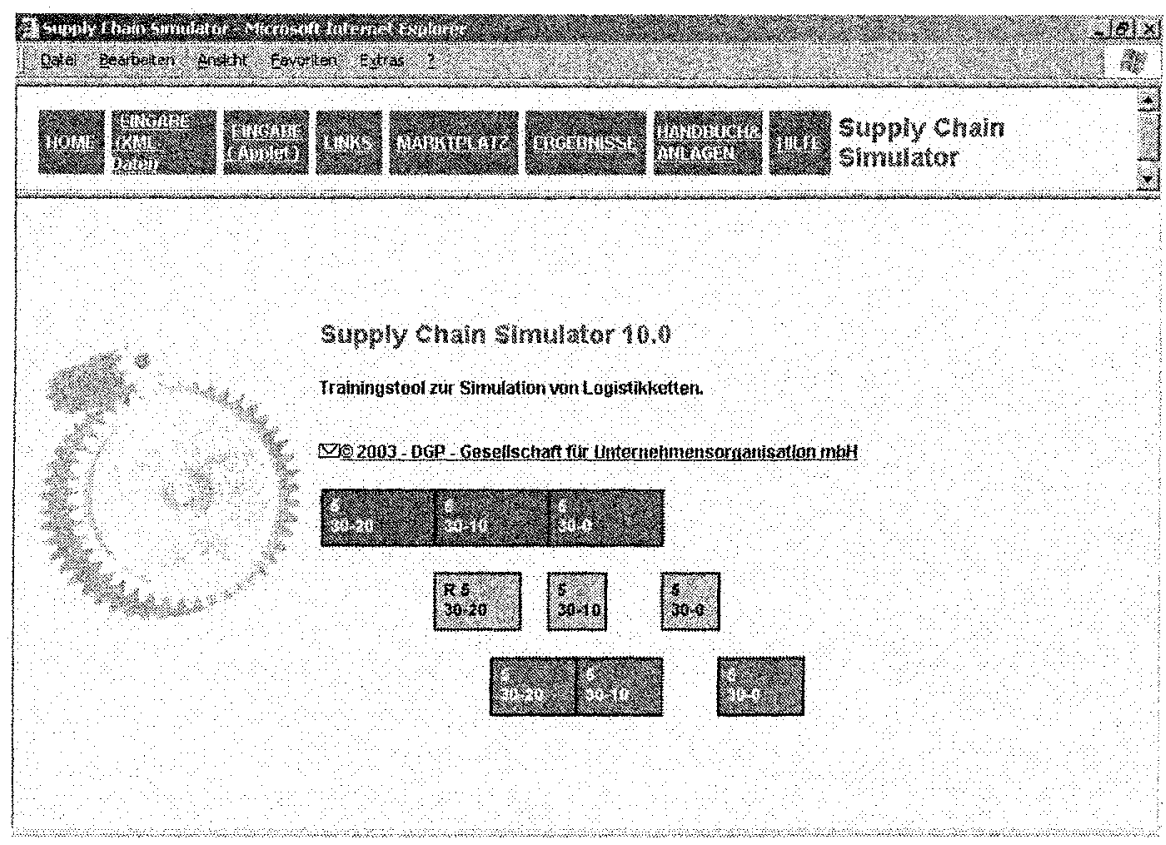

Figure 9. SCS access

The applied server technology with its possibility of a central simulation of production plants, combined with standard methods of Internet communication, allow, for the first time, a geographically independent exchange of purchased parts and components, semi-finished products, final products and funds. This enables an international and extremely realistic business simulation. The design and implementation of cash flow, the information logistics, as well as the contract conditions are based on the same methods and technologies used in "real life", whereas the manufacturing of semi-finished and finished products is simulated by the simulation system. 
A continuous and global participation of educational institutions allows the creation of an international, simulated market. The multi-lingual versions of the concept and the cooperation of different universities in Germany, Austria and Greece brought this open concept to an international level for the first time. The first courses outside of the German-speaking countries were held at the Technological Educational Institute in Kavala (TEI), Greece.

However, not only universities all over the world might profit of such a concept. A LEARNTEC forum has shown particular interest in the problem of "Digital Divide", a program the UNESCO refers to as "Reach the Unreachables" with the goal to train people in less developed countries using modern media, such as, the new information and communication technologies, especially the Internet (KAPPEL 2002). The existing training concept can contribute greatly to that program. Furthermore it can be combined with a new approach for recruiting project teams for supply chain projects (WIENDAHL 1996; AUGUSTIN, KERN 2002).

\section{REFERENCES}

AUGUSTIN, Siegfried; GRAF, Karl-Robert:

Planspiele bei der Einführung kontinuierlicher Verbesserungsprozesse.

In: etz Elektrotechnik und Automation,

Düsseldorf, 124(1995)13-14, pp.12-17.

AUGUSTIN, Siegfried; KERN, Eva-Maria; HORNSTEIN, Elisabeth von:

Management von Supply Chain Projekten - Einsatz von Planspielen zur Optimierung der

Projektbesetzung.

In: Logistikplanung und -management, 8. Magdeburger Logistik-Tagung.

Hrsg.: SCHENK, Michael; ZIEMS, Dietrich; INDERFURTH, Karl.

Magdeburg, 2002, pp. 270-282.

DGP - Gesellschaft für Unternehmensorganisation:

Logistikplanspiele.

Karlsruhe: DGP, 2004.

http://www.logistikplanspiele.de, 05.04.2004.

GRAF, Karl-Robert; TERZIDIS, Konstantinos; AUGUSTIN, Siegfried:

Global Education Integrating Simulation and the World Wide Web for Creating Supply

Chains.

In: Current Trends in Production Management.

Eds.: ZÜLCH, Gert; STOWASSER, Sascha; JAGDEV, Harinder S.

Aachen: Shaker Verlag, 2003, pp. 25-33.

(esim - European Series in Industrial Management, Volume 6)

KAPPEL, Hans Henning:

LEARNTEC 2002: Internationalität wächst.

In: Frankfurter Allgemeine Sonntagszeitung,

Frankfurt, 27.01.2002, p. 70. 
LANG, Sabine; JUNG, Klaus-Peter:

Planspiele für die Praxis.

In: Logistik heute,

München, 23(2001)3, pp. 50-52.

RIIS, Jens O.:

Simulation Games in Production Environment - An Introduction.

In: Simulation Games and Learning in Production Management.

London: Chapman \& Hall, 1995, pp. 3-12.

THALER, Klaus:

Supply Chain Management.

Köln: Forbis, 1999.

WIENDAHL, Hans-Peter:

Fähigkeit zum Wandel und kurze Reaktionszeiten bestimmen den Erfolg.

In: Industrie-Anzeiger,

Stuttgart, 118(1996)34/35, pp. 28-31. 